\title{
O mito do "éxito" escolar das rapazas
}

\author{
The Myth of Girls' "Success" in School
}

\author{
Ana IGLESIAS GALDO \\ Universidade da Coruña \\ Pilar BALLARÍN DOMINGO \\ Universidad de Granada
}

\begin{abstract}
RESUMO: A aparente igualdade entre rapazas e rapaces nas aulas oculta camiños históricos diferentes, marcados por relacións de xénero desiguais, que persisten nelas de forma sutil. Baixo a sospeita de que tras o discurso do "éxito escolar das rapazas" se alimente a preocupación dos que conciben -moitos máis dos que o nomean- que o mellor servizo das mulleres á sociedade (maternidade, crianza, coidados familiares e traballo doméstico en xeral) se pode ver minado polo seu éxito profesional -cuestión que recobra novo valor cando a crise económica require fortes soportes familiares para xestionar a miseria social-, apelaremos ás contribucións feministas para comprender mellor a que se está a denominar "éxito", tarefa que entendemos prioritaria para desestabilizar algúns dos supostos que, coma este, están a imposibilitar a educación para a igualdade.
\end{abstract}

PALABRAS CHAVE: éxito/fracaso escolar, estudos feministas, educación, cidadanía, xustiza social.

ABSTRACT: The apparent equality between girls and boys in the classroom conceals the different historic trajectories marked by unequal gender relationships whose presence albeit subtle- can still be felt. There is some suspicion that behind the argument in support of "the academic success of girls" lies the concern of those who profess the idea -many more than those who talk about it- that the best way women can serve society (maternity, raising children, taking care of the family and household chores in general) could be undermined by their professional success. And this is a topic that takes on a new dimension when situations of economic crises demand strong family support to deal with social poverty. This article discusses the contributions made by feminists to understand what is meant by "success", a task we consider to be of high priority to refute some of the assumptions which, like this one, are trying to prevent equal education.

KEY WORDS: School success/failure, Feminist studies, Education, Citizenship, Social justice. 
Empezabamos o novo milenio con avances lexislativos en materia de igualdade ${ }^{1}$ que, se ben non garantían a supresión total das xerarquías de xénero instaladas no imaxinario colectivo e a práctica cotiá, contribuían a debater sobre os dereitos a unha cidadanía democrática plena e sobre modelos educativos máis radicais que, abertamente antisexistas, contribuísen á súa edificación.

Non obstante, estamos vivindo que a regresión é posible e avanza rápido², pero nada pode impedirnos reclamar a consideración debida ás contribucións dos estudos feministas e lanzar os seus interrogantes para desestabilizar algúns dos lugares comúns que, como 0 "éxito" e o "fracaso", distraen doutras preocupacións do sistema educativo, especialmente aquelas que imposibilitan a educación para a igualdade.

O abandono e o menor éxito académico dos rapaces que o das rapazas vaise instalando como unha preocupación difusa e confusa, no medio dos discursos que caracterizan un cambio de rumbo radical na dirección política con que se estreaba a primeira década do século XXI, que merece a nosa atención. Porque sería grave que neste novo milenio a lóxica da cidadanía, suplantada pola da mercantilización, e apoiada nunha racionalidade técnica, esquecese que as análises de xénero son cuestión fundamental de inclusión no currículo, se non queremos ver gravemente danadas as posibilidades de contribuír a unha cidadanía global e, polo tanto, a unha maior xustiza social.

\section{Orixe dunha dicotomía con cegueira de xénero: éxito/fracaso escolar}

Hai uns anos "a ninguén lle estrañaba que miles de alumnos deixasen de selo para incorporarse á actividade económica, particularmente se se trataba das tarefas domésticas, as mulleres, ou do traballo agrario e industrial, os homes"3. Ata a década dos 70 (Lei xeral de educación) o noso país mantivo un sistema dobremente dual. Por un lado segregaba por clase, ofrecendo unha educación para as clases traballadoras (primaria) e outra para as elites (bacharelato e formación superior). Por outro, segregaba por sexos, limitando as rapazas á educación primaria, ao entender que o seu futuro era o servizo aos demais no fogar e, en consecuencia, non considerando propio delas os niveis que se dirixían a actividades profesionais ou cargos da Administración, aínda non sendo excluídas

\footnotetext{
${ }^{1}$ Lei orgánica 1/2004, do 28 de decembro, de medidas de protección integral contra a violencia de xénero (LOVX, 2004); Lei orgánica 2/2006, do 3 de maio, de educación (LOE, 2006); Lei orgánica 3/2007, do 22 de marzo, para a igualdade efectiva de mulleres e homes (LOIE, 2007); Lei orgánica 4/2007, do 12 de abril, pola que se modifica a Lei orgánica 6/2001, do 21 de decembro, de universidades (LOU, 2007).

${ }_{2}^{2}$ Mentres escribiamos este artigo propoñíanse dous textos lexislativos que suporán un forte retroceso para a igualdade de xénero. Un, a Lei orgánica para a mellora da calidade educativa (aprobada no Congreso 09 de outubro e no Senado 023 de novembro) entraba en vigor o 30 de decembro e favorecerá un modelo de educación que segrega por sexo; outro, o anteproxecto da Lei orgánica de protección da vida do concibido e dos dereitos da muller embarazada, a reforma da lei do aborto aprobada o 20 de decembro polo Consello de Ministros que, de seguir a súa tramitación nos termos actuais, obrigaría ás mulleres a ser nais contra a súa vontade.

${ }^{3}$ Mariano Fernández Enguita, Luis Mena Martínez e Jaime Riviere Gómez, Fracaso y abandono escolar en España (Barcelona: Obra Social Fundación "la Caixa", 2010), 13.
} 
explicitamente do sistema universitario, e mesmo ter un crecemento importante na década dos sesenta.

A Lei de educación dos anos setenta, marcou para as rapazas un paso adiante ambivalente:

a) Ampliou a primaria (Ensino Xeral Básico) aos 14 anos, o que significou un crecemento importante da escolarización.

b) Declarou a súa pretensión de ofrecer a todos e todas a igualdade de oportunidades educativas no nome dunha sociedade máis xusta. Tratábase dunha "igualdade de oportunidades" que, segundo o Libro branco que serviu de base a esta, non era unha "igualdade a secas".

c) As escolas foron progresivamente converténdose en mixtas.

A igualdade de oportunidades, lonxe de entenderse, como sucederá máis tarde, como un trato "idéntico", asentábase sobre o principio de diferenzas de natureza para cada sexo que remarcara o proxecto franquista. Se ben se abría ás rapazas a formación considerada propia para a súa incorporación ao mundo laboral -que aplaudimos-, pouco a pouco os contidos relacionados con tarefas reprodutivas -exclusivos da educación feminina desde a orixe do noso sistema educativo- fóronse desvalorizando ata desaparecer, ao non se considerar dignos da súa inclusión no currículo común obrigatorio para todo o alumnado.

Pero as mulleres deron un paso adiante e a súa presenza na Universidade, crecente a partir dos sesenta, viuse notablemente ampliada, a pesar de que unha elevada porcentaxe das licenciadas, nos anos setenta, non exercían: o modelo de "excelencia" para as mulleres pouco cambiara, só engadía un título ao seu "dote".

Iniciábase así no noso país o modelo de xustiza meritocrática que prometía que todas e todos participarían da mesma escola sen distinción de clase, raza ou sexo e, ao ser iguais no acceso, instaurábase un principio educativo aceptado socialmente como xusto, fronte a aquel outro que reservaba o ensino secundario e superior a unha elite. Para dicilo en palabras de Dubet, "mentres as desigualdades derivadas do nacemento e a herdanza son inxustas, a igualdade de oportunidades establece desigualdades xustas ao abrir a todos a competencia polos diplomas e as posicións sociais"5.

Porén, esta escola mixta, a das oportunidades, creou novas xerarquías que se presentan como naturais e aceptables, dando entrada ás rapazas a un currículo que se deseñou para os rapaces, para preparalos para as actividades produtivas, sen ter en conta as diferenzas construídas e a permanencia de dous modelos de excelencia social diferentes para varóns e mulleres, isto é, con absoluta cegueira de xénero.

\footnotetext{
${ }^{4}$ Ministerio de Educación y Ciencia, La educación en España. Bases para una política educativa (Madrid: MEC, 1969), 122.

${ }^{5}$ François Dubet, La escuela de las oportunidades ¿Que es una escuela justa? (Barcelona: Gedisa, 2005), 19.
} 
Posteriormente, os problemas parecen recruarse coas reformas comprehensivas do ensino e a ampliación da escolaridade obrigatoria aos 15 ou os 16 anos, xa que "a xeneralización do ensino secundario revelouse unha tarefa complexa e hercúlea", que crea dificultades "non soamente nas clases populares senón tamén, en boa medida e cada vez máis, nas clases medias. Así é como o fracaso escolar pasou de ser un sobreentendido aceptado por todos a un motivo de alarma social"'.

Non parece estraño que, nestes momentos, nun mundo cada vez máis globalizado e marcado pola sociedade da información, a todos preocupe a maior e mellor cualificación cando dela se fan depender as oportunidades sociais e laborais das persoas.

Éxito e fracaso, categorías dicotómicas, xorden así como dúas caras da mesma moeda no marco escolar, en que o fracaso pasa a ser unha das principais preocupacións sociais: "Afrontar o fracaso escolar non é xa simplemente combater a desigualdade nun aspecto da vida, no acceso a un ben, senón combater a desigualdade no acceso ao recurso clave da estrutura social e da distribución das oportunidades de vida individuais. De aí a súa centralidade"

A medida que foi crecendo a preocupación polo fracaso, as análises na busca de explicacións, que inicialmente se centraron nas desigualdades sociais, foron poñendo de relevo o éxito das rapazas.

\section{As cifras e as súas análises: os datos que importan}

A socioloxía da educación francesa dos anos sesenta e setenta, en especial os estudos de Bourdieau-Passeron e Baudelot-Establet, comezaron a constatar os mecanismos de produción e reprodución de desigualdades sociais, centrando a mirada nas clases sociais, pero moi pouco e non sempre se interesaron en analizar a cuestión desde a categoría sexo.

Así, "a igualdade de oportunidades" que se proclamaba na España dos setenta parecía converter a variable sexo en pouco pertinente, xa que as as diferenzas e discriminacións eran interpretadas fundamentalmente segundo a orixe de clase.

Os datos sobre éxito e fracaso comparando rapaces e rapazas espertaron numerosas "inquietudes", como sinalaría Pierrette Bouchard ${ }^{8}$ en Canadá a mediados dos noventa. 0 abandono e fracaso afectaban moito máis aos nenos que ás nenas e anunciaba que a fenda estaba a crecer.

\footnotetext{
${ }^{6}$ Fernández Enguita, Mena e Riviere, Fracaso y abandono escolar en España, 14.

${ }^{7}$ Ibid., 18.

${ }^{8}$ Pierrette Bouchard et al., De L'amour de l'ecole. Poinst de vue de jeunes de 15 ans (Québec: Editions du remueménage, 1997), 10-11.
} 
A preocupación pola incorporación da perspectiva de xénero ás estatísticas ${ }^{9}$, pola necesidade de recoller, recompilar e presentar os datos analizados por sexo, é relativamente recente no Estado español, a pesar de que, como sabemos, e ampliando a afirmación de Nancy Hafkin, "sen datos non hai visibilidade, sen visibilidade non hai credibilidade e sen credibilidade non hai prioridade"10.

No noso país, a pesar de que as institucións públicas foron incorporando as directrices dos organismos internacionais, a aposta por este tipo de políticas e, en particular sobre este ámbito, ten data recente. Pero os datos que ofrecía o Instituto da Muller, referidos ao curso 1993-1994 ${ }^{11}$, apuntaban xa a un maior rendemento académico das rapazas, aínda que as diferenzas con respecto aos rapaces non eran moi marcadas. Estes datos eran confirmados polo CIDE en $1999^{12}$, destacando que as mulleres proseguían con maior uidez o seu avance educativo mentres os varóns tendían máis a abandonar ou atrasarse.

Coa Lei orgánica 3/2007 do 22 de marzo, para a igualdade efectiva de mulleres e homes, introdúcense no seu artigo 20 normas específicas sobre a incorporación do enfoque de xénero nas estatísticas, o que implica incluír sistematicamente a variable sexo e elaborar novos indicadores que melloren o coñecemento da realidade e as potenciais desigualdades entre mulleres e homes. Para entón, as cifras do curso 2003-2004 ${ }^{13}$ xa fixeran saltar as alarmas ao mostrar que a escolarización das nenas estaba a ser maior que a dos nenos, sendo aos 16 anos a taxa de escolaridade feminina superior, en case 6 puntos, á masculina -90,7\% rapazas e 85\% rapaces-, e aos 17 anos a diferenza era aínda maior $-80,5 \%$ mulleres e $69,8 \%$ homes-. Estas cifras eran moi similares no curso $2004-$ 2005, segundo os datos oficiais do Ministerio de Educación e Ciencia ${ }^{14}$.

\footnotetext{
${ }^{9}$ Tal e como recolle o Informe do Instituto da Muller (2009), pódese comprobar que este proceso se inicia na Primeira Conferencia Mundial sobre a Muller en México (1975), ao poñerse de manifesto, por primeira vez, que a falta de estatísticas e datos desagregados por sexo, así como a presentación destes de modo axeitado para o seu uso por parte dos axentes decisores, é un dos obstáculos máis importantes que impiden cambiar a situación das mulleres. Foi necesario esperar unha década, ata a terceira Conferencia Mundial sobre a Muller de Nairobi (1985), para que se tomasen algunhas decisións neste sentido a nivel mundial, ao definirse 39 indicadores considerados como claves -entre eles a educación-, para identificar a situación das mulleres no mundo. 0 impulso definitivo foi a Cuarta Conferencia Mundial sobre a Muller (1995) en Beijing. Mesmo moitas persoas sosteñen que o verdadeiro nacemento das estatísticas con perspectiva de xénero, tal e como na actualidade son concibidas, ten aquí o seu punto de partida. Ten dúas implicacións fundamentais. En primeiro lugar, a asunción dun conxunto de obxectivos que se recollen na Plataforma de Acción de Beijing e que instan ao desenvolvemento das estatísticas de xénero e, por outro lado, a introdución do concepto de "transversalidade da perspectiva de xénero".

${ }^{10}$ Cecilia Castaño Juan Martín e Susana Vázquez, "La brecha digital de género: acceso, uso y habilidades", en La segunda brecha digital, dra. Cecilia Castaño (Valencia: Cátedra, 2008), 56.

${ }^{11}$ Instituto de la Mujer, Las Mujeres en cifras (Madrid: Ministerio de Trabajo, 1997).

${ }^{12}$ Centro de Investigación y Documentación Educativa (CIDE), Las desigualdades de la educación en España II (Madrid: Centro de publicaciones del MEC, 1999), 26-27.

${ }^{13}$ Ministerio de Educación y Ciencia, Datos Básicos de la Educación en España en el curso 2006/2007 (Madrid:MEC, 2006). http://www.20minutos.es/data/adj/2006/09/12/271.pdf

${ }^{14}$ Ministerio de Educación y Ciencia, Datos y cifras. Curso 2007-2008 (Madrid: MEC, 2007). http://www.mec.es/ $\mathrm{mecd} / \mathrm{jsp} /$ plantilla.jsp?id=313\&area=estadisticas
} 
As fontes estatísticas (MECD, 2012 ${ }_{b}{ }^{15}$; MECD, $2012_{a}{ }^{16}$; Informe de EURYDICE, 2011 ${ }^{17}$ ) recollen as diferenzas no acceso e nos logros do alumnado en función do sexo e visibilizan o "éxito" das rapazas anunciando que:

a) Teñen maiores taxas de éxito as rapazas fronte ao maior abandono e atraso dos rapaces en primaria, secundaria obrigatoria e bacharelato.

En primaria xa se observa "unha notable vantaxe das nenas sobre os nenos: dous puntos menos de repetición, que sobre unha media de seis son moitos"18.

Ao finalizar a educación primaria, con 12 anos, obsérvase de novo "a vantaxe feminina: máis de cinco puntos ao seu favor en 2006-2007"19.

Sobre taxas de promoción en secundaria do curso 2006-2007 constátase de novo "a superioridade académica das mulleres sobre os homes, aos que superan en todos os cursos por unha diferenza de seis a oito puntos porcentuais..., as mulleres avantaxan claramente aos homes á hora da graduación: 78,6\% fronte a 64,9\% no curso 2006-2007, case 14 puntos porcentuais de diferenza"20.

En bacharelato "as mulleres, ademais de chegar en maior proporción, obteñen mellores resultados que os homes respecto á promoción, sacándolles ata case seis puntos de diferenza (en primeiro curso, o $73,3 \%$ dos homes ascende, fronte ao $79,4 \%$ de mulleres; en segundo curso, $070,1 \%$ dos homes, fronte ao $75,6 \%$ de mulleres)"'21.

b) Obteñen mellores resultados en todas as disciplinas e niveis universitarios.

O $54,1 \%$ do total das estudantes universitarias son mulleres e a súa proporción increméntase entre os titulados universitarios ata situarse no 59,7\%. A presenza das mulleres é maioritaria en todas as ramas, coa excepción das titulacións técnicas. $\mathrm{Na}$ universidade, as mulleres obteñen taxas de rendemento máis elevadas que os homes en todas as disciplinas e en todos os niveis. En termos globais, o rendemento das mulleres no curso 2010-2011 superaba en 10 puntos porcentuais os homes: $71.4 \%$ fronte ao $61.8 \%$.

\footnotetext{
${ }^{15}$ Ministerio de Educación, Cultura y Deporte, Datos y cifras. Curso escolar 2012/2013 (Madrid: MECD, 2012b). http://www.mecd.gob.es/dctm/ministerio/horizontales/estadisticas/indicadores-publicaciones/datos-cifras/datosy-cifras-2012-2013-web.pdf?documentld=0901e72b81416daf

${ }^{16}$ Ministerio de Educación, Cultura y Deporte, Datos y Cifras del Sistema Universitario Español: curso 2011/2012 (Madrid: MECD, 2012a). http://www.mecd.gob.es/prensamecd/dms/mecd/prensa-mecd/ actualidad/2013/01/20130118-datos-univer/2012-2013-datos-cifras.pdf

${ }^{17}$ Informe de EURYDICE, Diferencias de género en los resultados educativos: medidas adoptadas y situación actual en Europa (Madrid, Secretaría de Estado de Educación y Formación Profesional, 2011). http://eacea. ec.europa.eu/education/eurydice/documents/thematic_reports/120ES.pdf

${ }^{18}$ Fernández Enguita, Mena e Riviere, Fracaso y abandono escolar en España, 34.

${ }^{19}$ Ministerio de Educación y Ciencia, Datos Básicos de la Educación en España en el curso 2006/2007, 36.

${ }^{20} \mathrm{Ibid} ., 40$.

${ }^{21} \mathrm{Ibid} ., 59$.
} 
A diferenza é maior na rama máis numerosa, co 50\% de estudantes, Ciencias Sociais e Xurídicas, onde as mulleres logran un rendemento de $71,4 \%$ fronte ao $63,5 \%$ de homes ${ }^{22}$.

c) Mantense a división sexual na orientación profesional.

Na formación profesional, a división sexual mantense de forma clara no curso 20122013. As porcentaxes máis destacadas da presenza de mulleres son en Imaxe Persoal (94,8\%), Actividades Marítimo-Pesqueiras (93\%), Servizos Socioculturais e á Comunidade $(89,1 \%)$, Téxtil Confección e Deseño $(87,9 \%)$ e Sanidade $(82,1 \%)$, mentres os varóns monopolizan practicamente Mantemento e Servizos á Produción (98,1\%), Mantemento de Vehículos Autopropulsados (98\%), Electricidade e Electrónica (97,5), Fabricación Mecánica (97,1\%), Edificación e Obra Civil (95,2\%), Madeira e Moble $(94,7 \%)^{23}$.

A presenza das mulleres é maioritaria en todas as ramas universitarias, coa excepción das titulacións técnicas (en Ciencias da Saúde o 71,3\% son mulleres, en Ciencias Sociais e Xurídicas o 61,3\%, en Artes e Humanidades o 62,1\% e en Ciencias o 55,1\%). Porén, na rama de Enxeñaría e Arquitectura a porcentaxe de mulleres sitúase no 26,7\%. O 55,7\% das mulleres fronte ao $41,4 \%$ dos homes estudan algunha titulación do ámbito de Ciencias Sociais e Xurídicas. 0 15,7\% das mulleres realiza algún estudo na rama de Ciencias da Saúde fronte ao 7,5\% dos homes. Non obstante, o 37,4\% dos homes realiza estudos de Enxeñaría ou Arquitectura e só un 11,6\% das mulleres. Segregación horizontal que se corrobora no Informe de EURYDICE de $2011^{24}$.

As análises destes datos seguen, con todo, sen establecer unha conxugación entre xénero e outras categorías ás que atravesa como clase social, idade, comunidade cultural, orientación sexual, ou situación xeográfica.

\section{0 que non explican as cifras}

Parece lóxico que as análises dos datos se centren no que se revela como problema: 0 maior fracaso dos rapaces. Parece inevitable que iso implique indagar no que se presenta como "a outra cara da moeda". Optaremos nesta ocasión por destacar algúns aspectos parciais que sirvan ao noso propósito: comprender mellor a que se está a denominar "éxito" das rapazas.

Entre as razóns que buscaban explicar este feito, parece oportuno sinalar a que consideraba que as nenas e as mozas se adherían á escola porque era a institución que mellor, ou menos mal, as trataba. Baixo este argumentario, tamén parecería razoable afirmar que o seu éxito se deba a que se adecúan mellor "aos requisitos e criterios de excelencia escolar que a institución manexa"25 pero isto, a noso entender, explica pouco.

\footnotetext{
${ }^{22}$ Ministerio de Educación, Cultura y Deporte, Datos y Cifras del Sistema Universitario Español: curso 2011/2012, 13.

${ }^{23}$ Ministerio de Educación, Cultura y Deporte, Datos y cifras. Curso escolar 2012/2013, 22.

${ }^{24}$ Informe de EURYDICE, 27-28.

${ }^{25}$ Carmuca Gómez et al., Identidades de género y feminización del éxito académico (Madrid: CIDE, 2001), 97.
} 
Dar por suposto que as rapazas teñen máis éxito no sistema educativo é hoxe unha evidencia comodamente instalada no imaxinario colectivo e, aínda recoñecendo que os motivos non están claros, as razóns que se esgrimen seguen sendo moi limitadas ao decantarse por aspectos "madurativos" de tinguidura bioloxicista. Como sinalan Carmuca Gómez et al. "o máis razoable é asumir que o proceso de desenvolvemento durante a puberdade favorece o mantemento da disciplina, a atención e a orde de traballo entre as rapazas en moita maior medida que entre os rapaces"26.

Certamente explicar este feito require atender a aspectos moi variados e complexos que teñen que ver, como diciamos, coa concepción de "éxito" que comunmente se manexa. Perrenoud explica que para ser bo alumno ou alumna non chega só con dominar o currículo, senón que require tamén, e quizais máis, comprometerse nas actividades propostas ou impostas e respectar as regras. Isto é, para alcanzar o estatus de excelencia escolar resulta imprescindible certo grao de conformidade.

Conformidade coas convencións gráficas, lingüísticas ou matemáticas; pero conformidade tamén coas normas morais, en relación cos outros e coas tarefas propostas. Seguindo a argumentación do brillante sociólogo, se un bo traballo escolar se caracteriza -entre outros asuntos-, por non ser retribuído, en boa medida imposto, fragmentado, repetitivo e supervisado constantemente, sen dúbida as rapazas saben moito disto, xa que estes requirimentos ilustran á perfección as competencias do traballo doméstico e de coidados, desenvolvidas fundamentalmente polas mulleres ao longo da historia. Velaí unha das (e)videncias do éxito escolar máis desatendida: "Ter éxito na escola supón aprender as regras do xogo!"27.

Porén, o éxito académico non se traduce en situacións máis vantaxosas para as mulleres no mercado laboral. Por un lado, porque como di Terry Wrigley, "a investigación da eficacia escolar (IEE) deriva cara aos resultados susceptibles de ser medidos, e especialmente as puntuacións dos exames"28, ninguneandose así, en nome da obxectividade e eficacia, outros resultados que tamén son producidos pola escolarización e que non se axustan a eses moldes de medida. Por outro, porque as orientacións profesionais das rapazas, como adoita afirmarse sen maior re exión, canalízanse cara a profesións feminizadas. Para unha análise rigorosa, é necesario considerar que, se ben cando crece a presenza das mulleres na universidade o fai en todas as carreiras, ao mesmo tempo os homes aumentan a súa proporción nas máis tradicionalmente masculinas e redúcese a súa presenza nas máis feminizadas, producíndose así a división dos territorios científicos por sexo. Comprender esta realidade nas súas dimensións máis profundas require, segundo Nicole Mosconi ${ }^{29}$, acudir a múltiples explicacións subxectivas, entre as que apunta que as rapazas nas súas

\footnotetext{
${ }^{26}$ Judith Rich Harris, The nurture assumption (Nova York: Free Press, 1998), cit. en Fernández Enguita, Mena e Riviere, Fracaso y abandono escolar en España, 81.

${ }^{27}$ Philippe Perrenoud, La construcción del éxito y del fracaso escolar. Hacia un análisis del éxito, del fracaso y de las desigualdades como realidades construidas por el sistema escolar (Madrid: Morata, 1990), 223-226, 218. ${ }^{28}$ Terry Wrigley, Escuelas para la esperanza. Una nueva agenda hacia la renovación (Madrid: Morata, 2007), 27.

${ }^{29}$ Nocole Mosconi, Femmes et savoir. La société, l'école et la división sexuelle des savoires (París: Editions L'Harmattan, 1994), 110-111.
} 
decisións operan con eleccións racionais contrarias ao estereotipo tradicional pero teñen en conta de xeito realista as posibilidades efectivas de emprego que o mercado laboral lles ofrece. As estatísticas mostran que as mulleres cunha formación e titulación "non tradicional" teñen máis dificultades para atopar emprego.

Finalmente preguntámonos: o maior "éxito" académico das rapazas, ou tal como queda formulado o seu presunto control das regras de xogo, está a significar para elas maiores privilexios? Que papel está a desempeñar nesta situación o currículo oculto?, e o profesorado?.

\section{A (e)videncia do currículo oculto}

Un dos mitos sobre os que se asenta o sistema educativo é a pretendida naturalidade e obxectividade, xustiza meritocrática, na escolarización, o que leva a asumir como certeza que a escola é igual para todo o alumnado. Pero pretender proporcionar o mesmo non quere dicir que na escola se aprenda todo o que se deseña, nin que todo o alumnado aprenda de igual xeito e, lonxe de promover maior igualdade, pode contribuír a reproducir as principais discriminacións da sociedade. De feito, se ben a condición de cidadanía parte da premisa de igualdade entre os seres humanos, non necesitamos demostrar que na escola, como na sociedade, a desigualdade derivada das estruturas patriarcais é unha realidade, mentres que a igualdade da cidadanía pertence ao ámbito da utopía ${ }^{30}$.

Interesarnos polo que se aprende durante a experiencia escolar é achegarnos ao currículo real, isto é, a relación producida entre o que se di que se ensina e todo aquilo que se aprende aínda sen ser intencionado. O currículo explícito ou oficial aparece claramente re ectido en normas legais, contidos mínimos obrigatorios ou programas oficiais, así como a través dos proxectos educativos de centro e a concreción que cada docente desenvolve na aula.

Na práctica escolar tamén se aprenden certas destrezas, actitudes ou valores que, a pesar de que nunca chegan a explicitarse como metas educativas, se adquiren coma se fosen experiencias naturais, coma se non puidesen ser construídas doutro xeito. Este tipo de aprendizaxes enchen de contido o chamado currículo oculto que, tal e como o entende Marina Subirats, "refírese ao conxunto de prácticas habituais no sistema educativo que non están explicitadas de forma patente, pero que forman parte dos hábitos da docencia, tanto en termos de atención ao alumnado como de observacións, valoracións etc. que 0 profesorado realiza" ${ }^{31}$.

No mesmo sentido exprésase Jurjo Torres cando explica que o currículo oculto, lonxe de ser froito dunha planificación "conspirativa" do colectivo docente, ao funcionar dun

\footnotetext{
${ }^{30}$ Vid. Ana Sánchez Bello e Ana Iglesias Galdo, "Curriculum oculto en el aula: estereotipos en acción", en Educar en la ciudadanía. Perspectivas feministas, ed. Rosa Cobo (Madrid: Los libros de la Catarata, 2008), 123-150.

${ }^{31}$ Marina Subirats, "La educación de las mujeres: de la marginación a la coeducación. Propuestas para una metodología de cambio educativo", en Género y currículo escolar, comp. Carmen Rodríguez (Madrid: Akal, 2006), 234 .
} 
xeito implícito, xoga un papel destacado na configuración de contidos culturais, rutinas, interaccións e tarefas escolares dos que nin o colectivo docente nin o alumnado adoitan ser plenamente conscientes. Isto explicaría á súa vez que dea como resultado unha reprodución das principais dimensións e peculiaridades da nosa sociedade ${ }^{32}$.

Queremos destacar o (sobre) peso que ten na configuración das identidades das persoas máis novas o papel deste tipo de saberes, pois o aprendido durante a experiencia escolar, como xa sinalamos, é moito máis amplo, profundo e complexo que o coñecemento derivado das diversas disciplinas académicas; é algo que chega a enraizar no máis fondo do alumnado e que produce efectos moito máis duradeiros que aquela outra información que, en maior ou menor medida, acabará esquecendo.

Considerado desde a coeducación, o currículo oculto pode intervir na discriminación que na actualidade, con vellas e novas caras, persiste en prácticas escolares que contan con gran poder para conformar dicotomicamente as identidades de xénero. Esta realidade escolar convértese nun potente freo para a acción educativa antisexista. Como é ben coñecido, os sexismos non se aprenden só na escola, pero como un dos principais intermediarios culturais que a sociedade ofrece a nenas e nenos é o colectivo docente, é innegable o seu poder para contribuír á reprodución ou á supresión da desigualdade de xénero.

Neste sentido, o contexto ten o desagradable costume de parecer algo dado e polo tanto case sempre claro e non problemático, cando, en realidade, non adoita ser así. Os criterios de organización e distribución nas diferentes actividades diarias, a selección das diversas propostas -literatura, vídeos, xogos-, os exemplos inventados, a forma de ser e de relación en tanto referentes do mundo adulto e tamén o perfil de infancia e xuventude que se usa como referente normalizado son representacións de modos de vida non carentes de perspectiva e con implicacións importantes na configuración das identidades do alumnado.

O feito de que, polo xeral, non se teña consciencia de utilizar estes modelos culturais, fai que gran parte do pensamento docente estea, en certo sentido dado, polas institucións sociais, pero coa particularidade de que, como avisa Montserrat Moreno "os modelos de comportamento actúan como organizadores inconscientes de acción e é esta característica de inconscientes, o que os fai máis dificilmente modificables"33; e para que isto non aconteza hai que recoñecer os mecanismos inconscientes de transmisión do modelo que queremos modificar.

Como é posible que se asuma como evidencia indiscutible o "éxito" das rapazas, cando aínda se segue detectando sexismo nos contidos que se transmiten explícita ou implicitamente e na linguaxe que se utiliza nas aulas, cando a organización escolar cambiou pouco, a pesar dalgunhas aparencias froito de certa énfase na idea de igualdade entre varóns e mulleres, e cando se manteñen importantes elementos de

\footnotetext{
32 Jurjo Torres, El curriculum oculto (Madrid: Morata, 1991).

${ }^{33}$ Montserrat Moreno, Como se enseña a ser niña: El sexismo en la escuela (Barcelona: Icaria, 1993), 22.
} 
discriminación, cuestións todas elas que viñemos denunciando insistentemente e que brevemente apuntaremos aínda que non abundemos nelas? ${ }^{34}$. Pois como sinala Rosa Cobo, "a socialización de xénero, como as outras socializacións, só pode ser combatida cando se ten conciencia da súa existencia, é dicir, cando os individuos se dotan de marcos interpretativos da realidade social que desvelan as xerarquías non lexítimas, as dominacións e as asimetrías sociais"35.

A organización formal dos centros continúa sendo un re exo da xerarquización socia ${ }^{36}$, como mostran os traballos de Eva Antón e de Carmen Gregorio ${ }^{37}$. A escasa representación das profesoras nos niveis de decisión e dirección e a maior presenza de mulleres entre 0 persoal menos cualificado, pon de manifesto a persistencia de desequilibrios entre homes e mulleres nun espazo cuxa función é educar, reforzando así no alumnado a idea do papel secundario das mulleres e da división sexual do traballo.

O uso do espazo escolar segue restando protagonismo ás nenas. O patio, o espazo de convivencia, de xogo e de lecer continúa sendo un couto privado dos rapaces case na súa totalidade ${ }^{38}$. Son os rapaces os que ocupan mellores posicións tendo en conta o significado e valor dos diversos recursos educativos. As observacións sobre a ubicación delas e deles nas aulas dependendo de onde se sitúan os recursos e os postos privilexiados segundo tipo de materia e metodoloxía, pon de manifesto unha clara vantaxe dos varóns ${ }^{39}$.

A pouco que se afonde no estudo dos libros e materiais escolares, os estereotipos seguen presentes aínda que, no ano 2000 , se indicaba que se estaban a volver máis sutís $^{40}$, e 0 uso da linguaxe considerada xenérica segue favorecendo a identificación do masculino co universal e o esquecemento das mulleres e todo o relativo a elas.

\section{Narrativas do profesorado}

As desigualdades de xénero no medio escolar non son só froito da reprodución pasiva senón da participación activa das persoas que nela interveñen que, na súa interacción, transforman as asignacións das diferenzas xenéricas. Alumnado e profesorado son a un tempo reprodutores e axentes de cambio das prácticas. Pero a pesar de que nos últimos

\footnotetext{
${ }^{34}$ Pilar Ballarín Domingo, "Retos de la escuela democrática", en Educar en la ciudadanía. Perspectivas feministas, ed. Rosa Cobo (Madrid: Los libros de la Catarata, 2008), 151-186.

${ }^{35}$ Rosa Cobo, "Repensando la democracia: mujeres y ciudadanía", en ibid., 40.

${ }^{36}$ Eva Antón Fernández (comp.), Igualdad en las aulas. Educación secundaria (Valladolid: Junta de Castilla y León, 2006).

${ }^{37}$ Carmen Gregorio Gil, Violencia de género y cotidianidad escolar (Sevilla: Instituto Andaluz de la Mujer, 2006).

${ }^{38}$ Instituto de la Mujer, La situación actual de la educación para la igualdad en España (Madrid: Instituto de la Mujer, 2005). Marina Subirats e Amparo Tomé, en Balones fuera. Reconstruir los espacios desde la coeducación (Barcelona: Octaedro, 2007), ofrecen claves para identificar e modificar as relacións de poder, xeralmente invisibles, no uso de espazo non igualitario, ao considerar que, doutro modo, continuarían perpetuándose as diferenzas de trato entre os individuos en función do seu sexo.

${ }^{39}$ Gregorio, Violencia de género y cotidianidad escolar, 74.

${ }^{40}$ Instituto de la Mujer, La transmisión de los modelos femenino y masculino en los libros de enseñanza obligatoria (Madrid: Instituto de la Mujer , 2000); Nieves Blanco García, El sexismo en los materiales educativos de la ESO (Sevilla: Instituto Andaluz de la Mujer, 2000).
} 
tempos se observa unha nova configuración das diferenzas de xénero, a práctica escolar segue marcada por roles fortemente sexualizados.

O profesorado mantén crenzas con respecto ás capacidades e habilidades (nenas traballadoras e estudosas e nenos sans, bos e desorientados) moi asociadas ao modelo educativo mixto e á súa vinculación co desenvolvemento das capacidades que teñen que ver co éxito no ámbito público, consideradas masculinas (competitividade, seguridade, forza...) e relegando outras consideradas femininas (sensibilidade, tenrura, afectividade...). Neste sistema de asignación dunha identidade de xénero diametralmente oposta para cada sexo, o lado masculino é considerado o referente, e ademáis o define o seu oposto na relación: sensibilidade/ ausencia de racionalidade, subxectividade/ ausencia de obxectividade; pasividade/ ausencia de actividade, pensamento/ exento de sentimentos; a razón debe dominar ás emocións. Premiase así "o mundo laboral e público sobre 0 doméstico e privado, o traballo retribuído sobre o voluntario, a produción sobre a saúde e o benestar, a racionalidade sobre a emotividade, a competitividade sobre a cooperación, os deportes competitivos sobre os xogos, a rapidez sobre a re exividade, a palabra sobre 0 silencio"41.

Na escola "hai de todo como na sociedade". Esta adoita ser unha idea comunmente admitida que mostra a aceptación das condicións de desigualdade como un feito natural e que alcanza ás desigualdades de xénero de forma especial. Non obstante, non parecen utilizarse no marco escolar as explicacións desenvolvidas para o social, en especial no que ao desenvolvemento da igualdade entre homes e mulleres se refire. Tanto profesoras como profesores -salvo honrosas excepcións- en nome da neutralidade e a non discriminación, esfórzanse en non facer diferenzas entre rapazas e rapaces. Así, con frecuencia, afirman que "todo o alumnado é tratado por igual" como unha medida xusta, obviando a virtualidade de medidas compensatorias e de acción positiva para intervir sobre as raíces das desigualdades.

Mais nin sequera é certo que o trato sexa igualitario. Mentres, as mensaxes emitidas polos estudantes varóns seguen tendo un valor diferente ás emitidas polas alumnas ${ }^{42}$. Ese valor diferencial que o profesorado outorga ás palabras dunhas e outros, con independencia da inlfuencia que puidera ter nos resultados académicos, xera nas persoas unha medida do maior ou menor valor transformador destas e da súa incidencia na realidade en que se insiren, como sinala a profesora Gregorio. Así, as rapazas, percibidas como menos desafiantes da autoridade ou con reaccións de menor agresividade, son máis ridiculizadas -así din sentilo elas mesmas- ao ser utilizadas polo profesorado para realizar sobre as súas condutas as re exións morais que non se realizan no caso dos seus compañeiros varóns por temor a maior desorde ${ }^{43}$.

\footnotetext{
${ }^{41}$ Amparo Tomé, "La construcción de las identidades masculinas y femeninas en la escuela", en Educar en femenino y masculino,dta. Nieves Blanco (Madrid: Akal, 2001), 90.

${ }^{42}$ Gregorio, Violencia de género y cotidianidad escolar, 24.

${ }^{43}$ Ibid., 25-41.
} 
As recriminacións de carácter moral dirixidas ás rapazas por parte de profesores e profesoras para manter a orde na aula, no caso dos rapaces convértense en expulsións, separación física ou silenciamento. O "que cales" ou "vaite para a rúa" dirixido ao rapaz que se enfronta á autoridade de forma violenta, adoita ser un "non molestes os teus compañeiros" no caso das rapazas. O profesorado, que se sente ameazado polos rapaces, utiliza á súa vez a ameaza con eles ${ }^{44}$. Deste modo, mentres as rapazas son tratadas como portadoras de maior moralidade, os rapaces, pola súa capacidade de violentar a orde, convértense en donos do espazo polo seu maior control dos mecanismos de dominación. Como temos re exionado noutros traballos ${ }^{45}$, non todos os rapaces se comportan de igual modo, pero os máis arquetípicos exercen a súa capacidade de dominio sobre os seus colegas.

Un dos factores que, con maior impacto, está a obstaculizar a corrección destas ideas e prácticas sexistas, e que contribúe poderosamente á reprodución do androcentrismo, é a formación de profesorado. Na maioría das disciplinas universitarias ignóranse os coñecementos achegados desde 0 feminismo e as análises de xénero ${ }^{46}$ e, salvo casos excepcionais, é frecuente que se inclúa un apéndice ou un engadido "de xénero" no programa da materia sen que supoña a súa revisión xeral.

A invisibilidade das achegas feministas e da contribución das mulleres e, en consecuencia, a ausencia das necesarias explicacións ás desigualdades de xénero nos programas universitarios, está a contribuír non só a que futuros profesionais teñan dificultades no recoñecemento da construción social e científica das desigualdades e se reforce a idea de universalidade androcéntrica, senón que, e sobre todo, contribúe a naturalizar as diferenzas de xénero ao non ser consideradas motivo de re exión e explicación científica.

As resistencias, crenzas e prexuízos de boa parte do profesorado obxecto das nosas entrevistas en profundidade, mostra un descoñecemento notable da produción científica que, nas últimas décadas, buscou explicar ás mulleres, a xénese das discriminacións que persisten, a construción social e científica das diferenzas etc., desde os distintos campos de saber. Ao considerarse o saber sobre as mulleres unha cuestión de actitudes e valores, de conciencia, non de ciencia, que ten máis que ver co social que co profesional, e ao dar a igualdade entre homes e mulleres por conquistada, non se (re)coñece o seu interese ${ }^{47}$.

\section{Cambios e persistencias nos estereotipos}

A aparente igualdade entre rapazas e rapaces nas aulas oculta camiños históricos diferentes, marcados por relacións de xénero desiguais, que persisten nelas de forma sutil.

\footnotetext{
${ }^{44}$ Ibid., 47.

${ }^{45}$ Ana Iglesias Galdo, Guía para practicar unha educación antisexista. I Itinerario de prevención integral da violencia de xénero, (Coruña: Concellería de Igualdade e Participación Cidadá, 2010), 28-35.

${ }^{46}$ Proyecto de investigación, "Evaluación de la incidencia de los saberes de las mujeres, feministas y de género en la docencia universitaria" Plan Nacional l+D+l Acción Estratégica sobre Fomento de Igualdad de Oportunidades entre mujeres y hombres 2007, No 074/07, IP: Pilar Ballarín (2008-2010).

47 Pilar Ballarín Domingo, "Docencia universitaria y conocimiento en torno al género. Resistencias, creencias y prejuicios", Cuestiones de género: de la igualdad y la diferencia, nº 8 (2013): 89-106.
} 
Pero moitas cousas tamén cambiaron, como mostra o tan nomeado "éxito" cuxa análise nos ocupa.

Os estudos sobre estereotipos de xénero sinalan que os trazos de masculinidade e feminidade que se atribúen a si mesmos homes e mulleres van cambiado, non obstante, as crenzas acerca do que os demais pensan segues ancoradas en estereotipos do pasado ${ }^{48}$ . Poderiamos pensar que nin a evolución do autoconcepto, nin os cambios sociais que se produciron axudaron a cambiar os estereotipos. Pero non é así, os estereotipos cambian aínda que talvez non o fagan no sentido e coa velocidade que nos gustaría.

Un recente traballo de Marina Subirats preséntanos un bo exemplo diso. A partir das historias de vida de mulleres nacidas nas décadas dos anos setenta e oitenta estudadas por Barbara Biglia, Ángel Gordo e Pilar Parra ${ }^{49}$, amósanos algúns cambios que se produciron nas mulleres pero mostrando tamén algúns dos fíos que nos conectan ao pasado: "As españolas de hoxe xa non asumen mandatos: ceden a impulsos, indagan nos seus desexos, corrixen as súas opcións. Tentean, proban, rectifican, aparentemente ao chou. Pero que é o que, no fondo, parece guialas, orientar as súas buscas e actitudes ?" 50 .

Vemos como o núcleo do xénero feminino construído historicamente, "o ser para outro", segue adherido os procesos culturais de socialización, isto é, forma parte da cotidianeidade, aínda que as súas versións sexan moi diversas. Tras as múltiples tarefas asignadas ás mulleres ocúltase a ausencia de identidade propia: "un ser que debe ignorarse a si mesmo, que non é senón a través doutro"51. E fainos observar como ese "ser para outro" se mantén: "Subterráneo. Inconsciente. Desorientado. Deslocalizado. Polo tanto, a miúdo irrecoñecible"52.

As mulleres gañaron en liberdade pero a liberdade conquistada, admitida a finitude dos amores, sitúase en poder cambiar se así se quere, pero "o outro" existe e resiste, aínda non se atreven a "ser para si":

Porque o que cambiou non é o mandato de ser para outro, para as mulleres, senón a concreción do outro. 0 "outro", que no pasado tiña unha figura xenérica, o home, e unha concreción estrita, o marido, o fillo, o noivo, o pai, o deus, o amo..., é agora unha figura baleira, que nin sequera ten forma humana. Pode ser unha causa, un movemento social,

\footnotetext{
${ }^{48}$ Esther Barberá Heredia, "Aportaciones psicológicas al estudio de las relaciones de género", en Género y currículo. Aportaciones del género al estudio y práctica del currículo, comp. Carmen Rodríguez Martínez (Madrid: Akal, 2006), 70.

${ }^{49}$ Pilar Parra Contreras: "El peso de la familia y del sistema educativo en las trayectorias de tres mujeres de clases populares, urbanas y rurales". Papers 98, ํ- 4 (2013): 709-729; Ángel Juan Gordo López: "Los procesos de subjetivación de las nuevas élites culturales. Itinerarios de autonomía e (in)dependencia emocional de mujeres de clase media". Ibid, 731-750; Barbara Biglia: "Experiencias fronterizas y efectos de las movilidades sociales y de clase". Ibid, 751-772. Textos vinculados ó proxecto de investigación dirixido por Julia Varela Fernández e financiado pola Secretaría de Estado de Universidades del Ministerio de Ciencia e Innovación (SEJ 2006-04140). ${ }^{50}$ Marina Subirats i Martori, "Mujeres y cambio social. En torno a los trabajos de Barbara Biglia, Ángel Gordo y Pilar Parra", Papers 98, ํㅜ 4 (2013): 773-777.

${ }^{51} \mathrm{lbid} ., 774$.

${ }^{52} \mathrm{lbid}, \mathrm{f75}$.
} 
unha idea, unha persoa, unha profesión ou unha construción mental de calquera tipo, sempre e cando cumpra coa condición de presentarse como algo que transcende a cada muller ${ }^{53}$.

E invítanos a entender que as cousas, dalgún modo, empeoraron polo con ito que se lles presenta ás mulleres entre "ser para outro" e "ser para si", cando todas as mensaxes do contorno procuran mantelas amarradas ao vello mandato.

Esta cuestión que tan sinxela e brillantemente, como sempre, nos formula a profesora Subirats, préstanos un potente argumento para explicar a maior adhesión das rapazas ao estudo segundo a clase social a que se pertenza:

As mulleres de clase media contan cun extraordinario recurso: 0 gusto pola cultura e a creatividade, e todas as portas que iso abre en termos de realización persoal, de entrega a unha tarefa socialmente valorada, que retorna autoestima e satisfaccións... pode mesmo ter unha transcendencia pública. Velaquí un "outro" solvente, que pode tiranizar, pero nunca decepciona ${ }^{54}$.

As de clase baixa "a miúdo acaban inclinándose pola maternidade, como o elemento finalmente máis sólido de vincularse" pero tamén, engade, que "frecuentemente, descobren, ás veces tarde, a vía dos estudos..."

As mulleres cambiaron, xa non entregan do modo clásico pero o norma permanece a través de novas formas de entrega: "...non descubriron aínda de todo que significa chegar a ser para si..." seguramente porque os resultados que observan froito do "vivir para si", que practicaron os varóns, non lles parecen convincentes.

\section{Reflexión final arredor da perversa sexuación dunha dicotomía}

Algunhas pistas explicativas fomos avanzando, outras quedarán esperando mellores argumentos xa que con esta re exión, parcial, incompleta e inconclusa, lonxe dun gran descubrimento, buscamos abrir interrogantes que axuden a afondar sobre o papel das institucións educadoras nas identidades das e os mozos; e nesta busca facemos nosas as interrogantes lanzadas por Ana Rubio: non saben os rapaces que aínda que non se esforcen moito sempre terán mellores oportunidades que as rapazas? Como actúa no fracaso escolar dos rapaces a presunción social de intelixencia que neles se deposita? Ninguén se preguntou en que falla o sistema educativo cando as que obteñen os mellores resultados educativos obteñen os peores traballos e salarios $?^{56}$.

Se as razóns do éxito ou fracaso son de xénero, talvez habería que formularse que o fracaso dos rapaces non é máis que unha nova forma de non se medir coas rapazas,

\footnotetext{
${ }^{53} \mathrm{lbid} ., 775$.

${ }^{54}$ Ibid., $776-777$.

${ }^{55}$ Ibid., 777.

${ }^{56}$ Ana Rubio Castro, "El abandono y la falta de éxito de los chicos en la escuela: un problema de género", CEE Participación educativa 11 (2009): 27-30.
} 
de non competir coas que consideran "distintas". Esta situación non é allea á cuestión da "violencia", pois ante o dominio intelectual das rapazas nas aulas, poden os rapaces buscar a súa primacía adheríndose a trazos estereotípicos que poden considerar que reforzan a súa identidade de xénero: a forza e a agresividade.

Son os datos oficiais os que presentan a cuestión do éxito/fracaso en función do sexo, sen contemplar outros aspectos, como clase, cultura, etc... Á primeira vista parecería froito da maior preocupación política pola igualdade, manifestada na lexislación recente, pero esta non parece ser a cuestión.

O éxito escolar non foi comunmente nomeado, xa que non é obxecto de preocupación. Foi a preocupación polo fracaso a que levou a destacar o éxito das rapazas, fronte ao obxecto real de preocupación que é, en definitiva, o fracaso dos rapaces. Esta confrontación en función do sexo, sen dúbida, ten sutís e variadas lecturas.

Nun contexto en que títulos e acreditacións foron progresivamente perdendo valor, inmersos nunha crise da denominada "sociedade do benestar" como a que está a vivir este país, en que os recortes sociais se converteron en branco principal e o neocapitalismo mostra un claro rearme patriarcal, cabe pensar que non é evitar o sexismo o que buscan estas análises.

Pola contra, induce a pensar que tras o discurso do "éxito escolar das rapazas" se alimenta unha importante e arraigada preocupación dos que conciben -moitos máis dos que o nomean- que o mellor servizo das mulleres á sociedade (maternidade, crianza, coidados familiares e traballo doméstico en xeral) se pode ver minado polo seu éxito profesional. Cuestión que recobra valor cando a crise económica require fortes soportes familiares para xestionar a miseria.

Talvez, cando se di "éxito" para referirse ás rapazas o que se pretende é deteriorar a mente, como sinala Emilio Lledó: "Dun xeito incrible. Unha forma de deteriorar a mente é deteriorar a linguaxe. Utilizamos palabras sen pensalas..." ${ }^{.7}$.

${ }^{57}$ Emilio Lledó, "La verdadera crisis es la de la inteligencia", El diario, 22 de novembro de 2013. 